\title{
The Nutrition of Cattle.
}

I $\mathrm{N}$ a previous article in our columns (NATURE, I925, vol. II6, p. I75) an account was given of some aspects of the feeding of cattle, including the method of indirect calorimetry, by means of which the value of different foodstuffs for maintenance and production can be determined, opportunity being taken at the same time to consider the relationship between the protein of the diet and the milk. The values assigned to different foodstuffs in nutrition depend not only on the accuracy of the experimental data from which they are estimated, but also on the correctness of the principles of the method of calculation used ; that finality has not been reached in either case appears from a number of papers which have recently been published dealing with the various methods and their difficulties, both of technique and of interpretation. Probably the most important general figure for a foodstuff is its net energy value, that is, the amount of energy contained in it which is available for maintenance and production after deducting the nonutilisable energy and that necessarily expended in the actual processes of utilisation of the remainder.

The net energy value can be determined divectly by means of the animal calorimeter. The heat given off by the animal is deducted from the energy value of the food as determined in the bomb calorimeter, the difference giving that available for the maintenance or increase of body weight, and for the production of milk. The method requires the use of complicated apparatus and a great attention to detail : to ensure accuracy, a number of corrections must be applied to the experimental results (M. Kriss, Jour. Agric. Res., 1925, vol. 30, p. 404), but with proper precautions the heat production can be satisfactorily estimated to within $\mathrm{I}$ per cent.

On the other hand, this estimation can be made indirectly, either by the use of the animal calorimeter again, but determining the oxygen consumption and the carbon dioxide production (instead of the heat emission) and calculating the latter from the amounts of protein, fat, and carbohydrate oxidised in the body, as determined from the respiratory exchange and the respiratory quotient, or, more simply, by deducting from the energy of the food the energy of the excreta plus that of the body tissue gained as determined from the nitrogen and carbon balances. This latter method is the one more generally used and gives results which compare well with the direct method (M. Kriss, loc. cit., p. 393): its most serious source of error appears to be the loss of material, from the urine and fæces, presumably through fermentation, during drying, preliminary to the determination of the energy value of the excreta in the bomb calorimeter: this loss can be minimised by drying at a low temperature.

In using the second of the two indirect methods described above, the 'balance' method, a source of error may be introduced by irregularity of excretion thus the fæces of a given period may not correspond accurately to that period, and this is especially the case when the diet is varied. R. W. Swift (Journ. Dairy Science, r925, vol. 8, p. 270) has made a study of the weights of fæces in metabolism experiments of varying length with cows and bullocks, and has found that the chances are $3 I$ to $I$ that, with an eight-day collection period, the errors of the averages will not exceed 7 per cent. and 5 per cent. respectively: it is probably better to ignore the first few days on a new ration: hence the entire period should last about a week.

If an animal neither loses nor gains weight over an experimental period, the heat production will equal the available energy of the food: but only rarely does this occur; usually the calculated energy of the flesh and fat formed or lost from the body must be subtracted from or added to the energy of the ration, to give the maintenance requirement. It is possible to avoid the calculation of the energy of the body tissue gained or lost by feeding the animal on two differing sub-maintenance rations, and calculating from the lessened loss of energy from the body on the higher ration, the increased amount of energy which must still be added to the latter to prevent any loss from the body; at the same time an estimation can be made for the heat production of the body when no food whatever is given. By increasing the diet above a maintenance value it is possible to obtain a figure for the amount of food which must be added for each pound of body fat laid on, an extremely important calculation for the fattening of animals.

Two assumptions are made in these calculations, which have been used chiefly by Armsby and Kellner respectively, as is pointed out by J. Wilson (Scient. Proc. Roy. Dublin Soc., I925, vol. I 8, pp. 77 and I I 7 ): first, that the maintenance requirement is the same whether food is being taken or not, or whether the ration is large or small, and secondly, that the maintenance requirement found with one type of food applies equally if the nature of the ration be changed, provided it has an equal calorific value. Wilson has made a critical examination of some of Kellner's and Armsby's results, from which he concludes that straw, for example, is less efficient than hay, as a ration, and that the food required by the bullock, whether idle or fattening, rises with the amount and kind of long fodder in the ration and also with the rate at which fat is being put on. Thus the maintenance requirement rises with an increase in the ration; in part this is due to the ensuing stimulation of metabolism which always occurs after food, so that the body lives less economically and a proportion of the energy of the food is wasted as useless heat. The increased heat production after a meal, especially onecontaining protein, is a well-known phenomenon. It is thus difficult to apply results obtained with one kind of food to an experiment in which another ration is given, or to assume that the energy value of a food will be the same at whatever level it is fed. Accurate results will be obtained only when the ration given is just sufficient for maintenance.

The force of these criticisms, however, is somewhat reduced by improvements in the methods of calculating results, including the adjustment of the daily heat production to a figure representing a standard day of twelve hours lying and twelve hours standing, as well as by improvements in technique. The latest method of calculation of the net energy values of feeding stuffs and some of the results obtained are given in a series of papers from the Institute of Animal Nutrition, Pennsylvania State College (M. Kriss, Jour. Agric. Res., I925, vol. 31, p. 469; E. B. Forbes and M. Kriss, ibid., p. ro8 3 ; E. B. Forbes, J. A. Fries, and W. W. Braman, ibid., p. 987 ; D. C. Cochrane, J. A. Fries, and W. W. Braman, ibid., p. 1055; E. B. Forbes, Proc. Am. Soc. Animal Production, I924, p. 23, and Science, I926, vol. 63, p. 3II ; and E. B. Forbes, J. A. Fries, and M. Kriss, Jour. Dairy Science, 1926, vol. 9, p. 15). The animal is given different rations during a series of experimental periods: by subtracting the heat production of a period on a lower diet from that of one on a. higher ration, the increased heat production due to the increase in the food is obtained. The net energy required for maintenance is the total heat production.

NO. 2976, VOL. I I 8$]$ 
in the period minus the total increase in this value due to the food, calculated from the average of the figures previously obtained. The total net energy of the ration is the average net energy for maintenance as found in the different experimental periods in which the particular food under consideration was used, plus the energy gained by the animal, which is determined by subtracting the total heat production from the metabolisable energy of the food.

By this method it is found that the results obtained in the different experimental periods usually agree fairly well, and it is easy to see and discard any abnormal set of figures. The authors are inclined to consider differences in maintenance requirements in different periods as due to experimental errors rather than to differences in the rations or in the plane of nutrition of the animal. On the other hand, from experiments on fasting animals it appears that energy is more efficiently utilised in sub-maintenance periods, so that consistent figures for net energy values of rations are more likely to be obtained when the plane of nutrition in the different periods does not vary too greatly, and thus that the results should be considered as applying accurately in other cases only when the animals are kept at a somewhat similar level of nutrition. A further point to which attention may be directed is the applicability of results obtained with a particular breed to animals of another breed or in a different country where the rations are almost certain to be different. F. J. Warth, L. Singh, and S. M. Husain (Memoirs Dep. Agric. India, 1926, vol. 8, p. I53) have established certain differences between their animals and those used in America in considering the requirements for milk production with Indian foodstuffs. These differences affect primarily the digestibility of the rations, due in part to their actual nature, but at the same time individual animals have their own characteristics.

In conclusion, it may be stated with confidence that there appears to be sufficient accurate knowledge of the efficiency of different rations for maintenance and production to enable the practical farmer to select from those available to him the most economical in meeting his requirements.

\section{Marine Biology at Plymouth.}

THE latest number of the Journal of the Marine Biological Association (N.S., vol. I4, No. 2, August I926, Ios. net) is full of good things. Dr. Orton resumes the interrupted publication of his studies on the rate of growth of marine organisms with a paper on the cockle. The investigations were carried out mainly in an experimental box laid down in the estuary of the river Yealm, in which the growing cockles were exposed to practically natural conditions, and the results have been checked by observations on near-by cockle beds. Apart from the definite determination of growth-rate-a matter of some economic importance, though it may be expected that the growth-rate will vary in different localities-the main interest of the paper lies in the study of the growth rings on the shell. It appears that, in the main, the deeply marked rings do indicate the winter checks in growth, and may be used-with cautionto determine the age of the cockle. Dr. Orton has, however, made the interesting observation that the mere removal of the cockles from the box for an hour or so for the purpose of examination suffices to cause the appearance of a "disturbance ring " on the shell. Specially well-defined rings are induced by the technique adopted of marking the shells for identification purposes with a file. Such disturbance rings can also be induced in the mussel. Further, in mild winters the winter-ring may become extended and spread out into several rings, so that accurate determination of the age by means of winter-rings is a matter of some difficulty, especially in the larger individuals. The paper would have been improved by the addition of a summary.

A second paper by Dr. Orton deals with the comparative effect of dilute but lethal solutions of T.N.T. on native and Portuguese oysters (Ostrea edulis and Gryphea angulata), and was carried out at the request of the Fisheries Department to clear up a point left undetermined in the course of Dr. Orton's elaborate study of the abnormal mortality among native oysters in I920-2I. It is said that the mortality did not affect the Portuguese oysters. Dr. Orton shows, however, that both species are about equally susceptible to T.N.T.

The next paper-a valuable study, by Dr. C. M. Yonge, of feeding and digestion in the oyster-also arises out of Dr. Orton's oyster-mortality investigations, and its genesis illustrates in a striking way how important it is that ' fundamental ' or purely scientific studies should accompany, or better still precede, any investigations directed towards a practical or economic end. It became apparent from Dr. Orton's own work on the mortality of oysters that not nearly enough was known about the normal physiology of the oyster for any one to say what conditions were normal and what were indicative of disease or pathological disturbance. Dr. Orton wisely pointed the moral by recommending a special research into the anatomy and physiology of the oyster, and of this Dr. Yonge's paper gives us the first fruits.

The paper seems to us wholly admirable. Dr. Yonge is of the modern school in combining anatomy with physiology, in studying form and function together. Considerable space is given to a clear and well-illustrated account of the anatomy and histology of the digestive apparatus both in the adult and in the larval oyster, and to a description of the amazingly complex system of ciliary currents by which the oyster collects and sifts out the tiny planktonic organisms on which it feeds, rejecting all such as are too large for it to deal with, and leading the rest over the palps into the mouth, down into the stomach and the digestive diverticula (commonly known as the "liver"). Other sections treat of assimilation, the digestive enzymes, the function of the crystalline style, and the storing of reserve products. Dr. Yonge finds that digestion is mainly intracellular-soluble matter and fine particles being ingested by the cells of the digestive diverticula, larger particles by the phagocytes present in all parts. This is demonstrated by ingenious feeding experiments with iron saccharate, with blood corpuscles of the dog-fish, with olive oil, and with the diatom Nitzschia. He rejects the theory of the Danish workers that the oyster is primarily a detritus feeder, and emphasises the importance of the smaller diatoms, peridinians, algal spores, and other microscopic vegetable matter.

It comes out clearly from Dr. Yonge's work, especially that on the enzymes present, that the oyster, like other lamellibranchs, is specially adapted for the digestion, assimilation and storage of carbohydrates. The rationale of fattening the oyster for market is, then, to supply it with plenty of microscopic vegetable food, as already indicated by Savage in a recent paper, and as realised empirically in some fattening ponds, particularly in France. It has been known for some time that the oyster stores its surplus nourishment mainly in the form of glycogen, which is no doubt 